\title{
FUNDAMENTOS DE EXÉGESIS LINGÜÍSTICA
}

\author{
Manuel Crespillo \\ (Universidad de Málaga)
}

\begin{abstract}
RESUMEN
During the second modernity the exegeses constitute the only possible way of bringing up to date the old romantic idea of the philology of the spirit, philology ruled by the ideal of the Absolute and conceived as an overvaluation of the subject, which implies to concede the primacy to the role of the language subject of art rather than to the language object of the great social mass.
\end{abstract}

I.

Al escribir La mirada griega $a^{1}$, pensé que la idea de enlazar el desarrollo de la cultura de Occidente con un carácter trágico y la de asociar el destino de Europa a unos orígenes también trágicos era tan importante como ligar el porvenir del arte europeo con el comentario de sus productos, de modo que pudiera funcionar una homología entre el comentario de una obra de arte y la propia cosa interpretada. Este anudamiento me permitió hablar de «recomienzo», no sólo en el sentido de volver a dirigir una mirada al origen griego de la cultura de Occidente, sino también porque se presentaba la posibilidad de ensanchar teóricamente el comienzo mediante un discurso que aspirara a ser inédito y que al mismo tiempo no sintiera la necesidad de renunciar a encerrarse en odre viejo. La instauración de una hermenéutica sobre la propia «cosa de arte» permitía reactualizar las categorías ilustradas y románticas que originaron la filología del espíritu.

1 M. Crespillo, La mirada griega, Málaga, Ágora, 1994. 
La posibilidad de tal ampliación abría grandes perspectivas a la actividad de Comentar, pues yo pensaba que en el campo de las manifestaciones artísticas, Europa, fiel a su tradición, se había comportado siempre como una unidad indivisa: los lenguajes de la música, del poema o del cuadro, y las múltiples interinfluencias entre las obras de arte, nunca estuvieron mediatizadas por límites ni fronteras. Así que mientras pensaba en el complejo mosaico de Europa, me preguntaba por la posibilidad de divulgar un comentario abierto que guardara una homología con la obra de arte interpretada. Si el arte fijaba la unidad de la vieja idea de Europa, el comentario de sus manifestaciones artísticas tendría que fortalecer, y no debilitar mediante relaciones particulares fragmentadas, esa misma vieja idea. Además, el comentario generado por el Gran Arte sólo debería ser concebido como la interpretación infinita que el propio objeto artístico provocara. Más que un simple comentario, esto podría ser denominado el Comentario. Sólo que, cuando se habla del Comentario, todo el mundo piensa en el único Comentario que dio vida al solemne Texto Bíblico, y para el que los estudios minuciosos de ese Texto reservaron el nombre de Exégesis. Un comentario que estuviera por encima de la Exégesis del Libro Primero, que fuera capaz de instaurar una universalidad entre las singularidades y que pudiera ser el lazo de unión de todas las formas de arte de la vieja Europa, no sabía yo cómo llamarlo. Al fin pensé que podría arrebatar el nombre a la Exégesis del Libro Primero y decidí hablar de ese comentario infinito en términos de Exégesis Profana. Inmediatamente, me apresuré a ligar el destino de la antigua Europa con el futuro de tales exégesis. La exégesis es, pues, el nombre moderno de la antigua filología del espíritu o de la cosa.

La aventura de enlazar el devenir de la vieja Europa con la suerte de las exégesis me obliga a efectuar dos aclaraciones previas. La primera consiste en poner de manifiesto que la Europa real de la contemporaneidad carece del más minimo interés para una exégesis. Las cualidades de la Europa actual, las que afectan a su mercado, ejército, unidad política, parlamento, máquina, técnica o progreso son ajenas por completo a la idea de Europa que las exégesis pretenden rescatar como valor puramente artístico. La libertad, que constituye un paradigma en el que se precisan todas esas cualidades - y que hoy dia parece un valor revolucionario en todo el mundo-, es una categoría que filosóficamente se revistió hace tiempo de un carácter exclusivamente formal, y que en su vertiente práctica es insolidaria con los grupos que no detentan formas grandilocuentes de poder. Convertida, a través de extraños vericuetos, en instrumento de control de la ciudadanía, funciona eficazmente en la anulación de la capacidad crítica de los individuos del Estado y necesita reproducirse incesantemente para permitir la perpetuación de castas políticas, económicas y de pensamiento en los grupos de poder. Pero el concepto moderno de libertad -y mucho menos las personas que contribuyen a la manipulación de su concepto- apenas si llega a despertar el comentario teórico de una exégesis, pues no guarda ninguna relación con la 
Libertad por la que tantos hombres nobles combatieron al iniciarse la modernidad ni tiene nada que ver con la Libertad ideal que tan apasionada y honestamente proclamaron Hegel, Schelling o Hölderlin. Cuando las exégesis hablan en nombre de la vieja Europa, se refieren a un concepto harto diferente. Proclaman, desde la gravedad del arte, la necesidad de volver la vista atrás a una Europa del pasado, a una Europa asustada y replegada sobre sí misma ante la carencia de límites exigible por el libre progreso, atemorizada por la idea de que la rectitud del hombre parece que se escapa, una Europa dispuesta a rescatar los valores artísticos y heroicos que un día la hicieron emerger en el firme horizonte de Occidente. Naturalmente, esto implica cobrar conciencia de que la vida heroica es ya un valor perdido en la contemporaneidad, con todo lo que ello supone para la destrucción del mito, de la leyenda, de las formas más egregias del arte y de las posibilidades de felicidad de la vida real.

La segunda aclaración concierne a la naturaleza de la exégesis como criterio de análisis en el horizonte de la cultura. En ciertos ámbitos especializados un exegeta es un personaje extraño y las exégesis no suelen estar demasiado prestigiadas por todas las connotaciones religiosas que el término conlleva. Por tanto, acepto la tarea de proponer un dominio inédito con el lastre inicial que linguísticamente tiene que soportar el término exégesis. De momento, mi criterio es que no hay otra palabra en las lenguas de Occidente que porte mejor el sentido de que cualquier futuro de Europa se liga ineludiblemente al recomienzo incesante de su origen artístico. Quizá el carácter profano que le añado, pueda ayudar a restablecer en gran medida su reputación. En cualquier caso, la exégesis moderna está pensada para afrontar el reto del desarrollo de Europa como una prolongación ininterrumpida de sus viejos mitos.

A fines del siglo XVIII y comienzos del XIX la vieja idea de la Europa moderna quedó fortalecida con los epígonos románticos de Kant, aquellos que dieron vida al antiguo idealismo alemán, si bien el horizonte de Occidente se fijó por primera vez en la Grecia heroica, en donde el honor, la gloria, el poder, la sinceridad, la muerte, etc., tuvieron un sentido sublime, pues permitieron el nacimiento de lo que muchos siglos después se denominaría humanismo. Al hablar de esa época, Festugière dijo que lo que caracteriza a una civilización no es tanto lo que los hombres hacen, el modo de comportarse prácticamente, como la idea sobre cómo deberían comportarse, es decir, una teoría de los valores, y especialmente del valor que se impone como un incondicional, como un Absoluto. El Alcibiades de Platón era la historia de un joven noble griego que remitía en última instancia a la dignidad esencial del sc: humano, lo cual debería ser el fundamento mismo de la Europa moderna.

Mucha gente se considera a sí misma humanista. Sólo que se ha llegado a comerciar tanto con las humanidades que una especie de modernas Sibilas han invadido su frágil entorno. Estas Sibilas son casi imperceptibles, aun cuando se tengan noticias de ellas porque organicen la vida de las modernas ciudades, se 
sienten en las aulas universitarias, dominen las instituciones y gobiernen los centros del Saber, los organismos y los grupos políticos, presidan los actos culturales, muestren la bandera de la forma, crean en los sistemas, les guste hacer análisis exhaustivos, transmitan conocimientos, defiendan la pedagogía, la didáctica, el progreso y el cambio de valores. Pero todas estas Sibilas olvidan que lo mejor que tenemos es aquella facultad que el griego designaba con la palabra noûs, esa extraña mezcla de inteligencia e intuición mística. La felicidad para el hombre distinguido era vivir conforme al noûs, y la vida acorde con el noûs era la vida teorética o contemplativa. Decía Aristóteles que una existencia así tenía que ser verdaderamente divina: «En la medida de lo posible, debemos hacernos inmortales y hacerlo todo para vivir de conformidad con la parte más excelente de nosotros mismos, pues el principio divino, por muy débil que sea en su peso, aventaja con mucho a cualquier otra cosa por su poder y valor ${ }^{2}$. Festugière, a quien debo esta reflexión, creía que ésas eran nobles palabras, lamentaba que nuestros jóvenes no conocieran ninguno de los capítulos de la Ética a Nicómaco y consideraba deplorable que nunca hubieran leído los adioses de Héctor y Andrómaca, la tristeza de Aquiles, el encuentro entre Aquiles y Príamo, ni tampoco una tragedia griega, ni la Apología de Sócrates, ni la muerte de Sócrates en el Fedón: «Hubo un tiempo en el que se leían en clase estas grandes páginas, en el que el alma dúctil del adolescente se penetraba de nobleza y hermosura. $Y$ esto confería al espíritu un cierto timbre de distinción; proporcionaba al alma un cierto gusto por el heroísmo, que convertía, en sentido estricto, al hombre en más esencialmente hombre. Éste era el sentido de lo que antaño se denominaban humanidades, y que hoy están a punto de desaparecer ${ }^{3}$.

La incapacidad de permanecer solos consigo mismos, la pérdida de una cierta cualidad de alma, que es cada vez más intensa en la Europa de la contemporaneidad, exige la inclusión de Occidente en el mundo de la Idea, el comentario para sí mismo de una idea que es porque es en sí misma. La extroversión de este en sí (de la idea en sí) genera un comentario permanente, un comentario $\sin$ fin de los valores que alumbraron las génesis de Occidente y de Europa. De todas las culturas conocidas, sólo Occidente ha necesitado de una manera especial remontarse al ser primigenio y comprender su origen para poder conocerse a si misma, para entender la esencia de su obra de arte y todo el probiema de su verdad. No es posible elaborar en Occidente una visión artística del mundo si ésta se desliga de la experiencia de su origen. Por eso decía Heidegger que el origen de la obra de arte únicamente podía ser el Arte, puesto que en su esencia la única verdad de éste sólo era un origen y no otra cosa. Hölderlin había nombrado esa señal cuando dijo que difícilmente abandonaba el lugar lo que moraba cerca del origen.

2 Aristóteles, Ética a Nicómaco, 7, $1177 \mathrm{~b}, 40$ ss.

3 A. Festugière, La esencia de la tragedia griega, Barcelona, Ariel, 1986, p. 105. 
El Arte origen es el movimiento incesante de la muerte, el fundamento que genera el gran abismo, y que llega incluso a anularse drásticamente a sí mismo. Aún en presencia de los dioses inefables, la muerte fue el símbolo que guió el comienzo del arte, de modo que Europa se acostumbró a ver tras cada cosa de arte la huella de alguna destrucción. En presencia de los mismos dioses, la obra de arte se funde con la muerte en un proceso unitario surgido de metamorfosis radicales en las que detrás del orden aparente se percibe el rastro difuso de grandes horrores, de conflictos salvajes y de confusiones profundas. El contenido de la obra es el caos, el cual, transmutado en representaciones, asume un principio de ordenación que se traduce en un universo creado. La belleza fascinante de la cabeza de Medusa tiene su origen en esta metamorfosis que convierte al arte en una especie de asesinato: No se puede hacer nada verdadero sin ser una pizca criminal, gustaba decir a Freud con cierta complacencia. Y todavía se puede avanzar más en esta dirección si se tiene en cuenta que la fusión del arte y de la muerte en el origen de Occidente es tan primitiva que se prolonga hasta el momento casi impensable - y me gustaría que se entendiera bien que estoy mirando el pasado con los ojos del futuro- en que aún no existían los dioses. Blanchot expresó de manera preciosa cómo podría ser este complicado proceso de unión: «Cada vez que, detrás de los dioses o en nombre de los hombres, la obra se hace oír, es para anunciar un comienzo mayor. Si los dioses parecen detentar las llaves del origen, si parecen las potencias primeras de donde todo se irradia, la obra, aun cuando expresa a los dioses, expresa algo más original que ellos, expresa la ausencia de los Dioses que es su Destino, expresa, más acá del Destino, la sombra donde éste habita sin signo y sin poder ${ }^{4}$. Cuando la obra no se puede apoyar ni en los dioses, que son su pasado, ni en la ausencia de ellos, que son su futuro, entonces se tiene que enfrentar obligatoriamente a sí misma, a la búsqueda infatigable del propio arte y a la experiencia de su origen. Este enfrentamiento es el abismo de muerte y vacío que sella nuestro Origen. $Y$ en el origen, ¿acaso el valor trágico y su necesidad de ser representado no fue uno de los valores constitutivos de la génesis de Occidente?

Sabemos que otras culturas que no acusan el fuerte sentido trágico de la existencia -que es indesligable del significado de Europa-, no precisaron crear arquetipos representativos para poder seguir viviendo $\mathrm{y}$, por tanto, no necesitaron nunca del teatro. En cambio, Europa sí necesitó de la ficción del teatro porque la Idea en sí apareció tras la experiencia de un considerable fracaso, surgió después de la más terrible destrucción que se pueda recordar en la convulsa historia del hombre - me estoy refiriendo a la destrucción de Ilión-, y después Occidente se fue forjando despacio a partir de un sentido extraordinario de culpabilidad y finitud, es decir, a partir de un valor hiperbólico sobre el error

4 M. Blanchot, El espacio literario, B. Aires, Paidós, 1969, pp. 219-220. 
y el extravío humanos, que llevaba a una pérdida de sentido, a un vivir como sombra de la que se desconocía tanto sus causas como sus fines, y cuyo efecto más importante llegó a ser incluso la ausencia de palabra y la utilidad del silencio. Ésta es a mi entender una gran Idea sobre Europa, y no tiene nada que ver con la que poseen los mercaderes ni los políticos que nos gobiernan - por más que se autoproclamen antiguos combatientes por la libertad-ni con la que propagan ciertos poetas locales, o algunos artistas miméticos y pensadores pasajeros que se sirven del mito de la libertad económica o social y que se someten a un poder político del que suelen ser sus aduladores y cómplices. También, tengo que decirlo para quien quiera entenderlo, Juvenal adulaba a Nerón; y, no obstante, éste nunca debería ser un caso digno de ser imitado.

Así pues, voy a sostener la tesis de que Europa no es más que el comentario de sus valores. A un comentario de esta naturaleza lo he llamado exégesis, y un exegeta debe ser aquel que comprendió que, dada la gran desorientación actual del arte y del pensamiento de Europa, no hacer el trabajo de la creación primitiva es efectuar el mayor de los esfuerzos. Pessoa, el gran poeta portugués, lo enunció de manera admirable: «Si existiese en el arte el oficio de perfeccionador, yo tendría en la vida de mi arte una función... Tomar la obra hecha por otro, y trabajar sólo en perfeccionarla. Así, tal vez, fue hecha la Ilíada... i Sólo el no hacer el esfuerzo de la creación primitiva! ¡Cómo envidio a los que hacen novelas, que las empiezan y las hacen, y las terminan!» ${ }^{5}$. Por tanto, la exégesis está ligada a la idea de que Occidente ha sufrido grandes y complicadas experiencias artísticas, y de que cuando se penetra por el interminable laberinto de sus huellas, hay que inventar la figura utópica del recreador sin rumbo fijo. Ese recreador es el tipo especial de filólogo del espíritu al que he denominado exegeta. De esta manera, un exegeta no puede ser un simple comentarista, sino una especie de fabulador capacitado para comprender que en el mundo de la exégesis el sujeto no es más que el objeto de sí mismo y que todo su proyecto se reduce a elaborar una sistemática sobre la recreación artístico-histórica. Esta recreación sólo es posible cuando se tiene conciencia de que los principios formales son valores detestables. Una arqueología sobre el universal fantástico que no permita sistematizar el horizonte de lo imaginario es el único camino posible. $Y$ en cualquier caso, el sujeto es una conciencia que posee una clara voluntad de ruptura con el mundo de las formas.

II.

Para una ontología del arte, la frágil esencia de Europa sólo es una exégesis, un comentario permanente de sí misma, el sujeto artístico de la historia del

s F. Pessoa, Libro del desasosiego, Barcelona, Seix Barral, 1984, p. 259. 
Saber. Las exégesis, entendidas como lectura libre y abierta en torno al arte de la palabra, tuvieron que rechazar durante mucho tiempo la dominación opresiva de las técnicas formales para poder defender su libertad. La primera repulsa moderna de esas técnicas en nombre de la exégesis se realizó recientemente en un libro del que yo mismo fui su autor ${ }^{6}$. Cuando se habla de la vieja Europa como de una idea cuya naturaleza esencial consiste en ser un comentario de sí misma, se precisa hacer la exégesis de las manifestaciones que esa idea produce para sí, se necesita comentar su música, su poesía, su arquitectura o su literatura, y de ahí la legitimidad con que deben plantearse los interrogantes siguientes: ¿Se pueden comentar las grandes realizaciones que la Idea en sí produce para sí, esto es, las realizaciones que sirven para perpetuarse interminablemente en la historia subjetiva del tiempo, sin ninguna otra finalidad que la de revelar para sí su ser en sí? ¿Se pueden comentar las manifestaciones artísticas sin perseguir fines cognoscitivos, y tratando sólo de revelar un estado especial de sensibilidad que no sea el efecto de la monótona aplicación mecánica de un modelo a una actividad creadora? Naturalmente que sí. Pero será necesario que cuando hablemos de la vieja Europa como de un comentario de sí misma o de una pura exégesis, no nos estemos refiriendo en ningún sentido a esa actividad pseudoformal y positivista que los filólogos denominan Comentario de Textos. Ese comentario no tiene nada que ver con lo que yo he llamado el Comentario en un artículo reciente ${ }^{7}$, no tiene relación alguna con la exégesis ni con la esencia de Europa ni con sus obras egregias de arte. Lo que denomino Comentario no es un ejercicio ni de análisis ni de síntesis, no es un sistema de aplicación de categorías previamente dadas a un universo artístico, ni el conocimiento de un objeto ni mucho menos el juego del «reconocimiento».

Pero ¿por qué el comentario no es otra cosa que la exégesis? Me gustaría organizar la respuesta a esta pregunta recordando algo que se suele olvidar con relativa frecuencia: hace ya doscientos años que los filósofos decidieron dejar de interpretar el mundo. El último que lo hizo fue aquel paseante solitario de Königsberg que respondía al nombre de Kant. Después de él aparecieron dos universos frente a frente. Uno estaba regido por el Comentario, el otro por la Forma, y ambos decidieron abandonar el papel invariable que durante más de veinte siglos había desempeñado la filosofía. Los comentaristas de Kant se llamaban Schiller, Fichte, Schelling, Hölderlin, Hegel o Schopenhauer, y decidieron, cada uno a su manera, abrir aún más el horizonte que Kant había despejado. Poco a poco fue surgiendo una amplia filosofía que llega a su punto culminante con Nietzsche, y que se caracterizó por el poderío irrefrenable de la charlatanería. Nietzsche es el último comentarista de la palabra que ha conocido Occidente.

M. Crespillo, Historia y mito de la lingüistica transformatoria, Madrid, Taurus, 1986.

7 Cf. M. Crespillo, «Teoría del comentario de textos», Analecta Malacitana, 1992, pp. 137 171. 
Al mismo tiempo, primero de modo imperceptible, y luego de manera contundente, un universo de forma comienza a ligarse con el positivismo, asoma muchos años después su cabeza vigorosa con el estructuralismo y el neoformalismo y, afortunadamente, ya inició su declive. Durante todo este tiempo el lenguaje asumió el yugo de convertirse en el objeto de la filosofía, y por eso Wittgenstein puede haber sido el pensador contemporáneo que más influencia ha ejercido sobre los filósofos actuales. Si el lenguaje se convertía en el objeto de la filosofía, ¿qué parcela tełsaber quedaría reservada para los lingüistas o los historiadores de la literatura? Cada vez más amedrentados, los lingüistas redujeron su campo de trabajo a descripciones de las lenguas, a análisis de niveles linguiísticos - pensemos, por ejemplo, en los fonetistas o en los lexicógrafos-o a problemas concretos de evolución histórica de las lenguas —el caso de los gramáticos históricos- o a la acumulación de informacioneslos historiadores de la literatura-, etc. De este modo, la filología, que era un reino ocupado por la libertad de imaginación y por la abertura de la creatividad, comprimió sus fines hasta tal punto que el problema del objeto, de los datos, de las fuentes, etc., terminó imponiendo su norma como filología de la letra. Sólo que si, como dijo una vez Kant, la filosofía también tiene su quiliasmo, yo estoy totalmente convencido de que ese quiliasmo no podía ser otra cosa que el lenguaje. Como sostuve en mi último artículo sobre Nietzsche, la aportación más importante de la filología al discurso filosófico de la modernidad fue esa transvaloración que se define como genealogía y que permitió a los filólogos de la palabra acusar con el terrible nombre de «crítica romántica» - por el sentido peyorativo implicado en tales palabras- la actividad hermenéutica de los filólogos del espíritu. Decía yo allí que «las técnicas de interpretación que promovieron el acceso hacia la genealogía provinieron del reino libre de la Filología, y que las mismas luchas políticas, causantes de dos interpretaciones radicalmente opuestas sobre la Antigüedad durante la Ilustración, también originaron en Alemania dos pensamientos filológicos, dos tendencias científicas si se quiere, absolutamente irreconciliables. Son aquellas cuya historia contó Howald en 1920 y que Barrios Casares recordó recientemente como la oposición entre los Wortphilologen (los filólogos de la palabra) y los Sachphilologen (los filólogos de la cosa) $\rangle^{8}$. El comentario irrefrenable de la palabra, el acompañamiento circular, voluntarista y retornable del espíritu de los textos artísticos, la comunión de una misma libertad y universalidad entre la cosa de arte y su comentario caracterizó desde su nacimiento a esa filología de la cosa o del espíritu opuesta a la actividad de los filólogos formales-, que arrancó de Schlegel y que continuaron Müller, Welcker o Creuzer. En realidad esta filología hunde sus raíces en la ilustración alemana, y especialmente en la agitada crítica de arte

8 M. Crespillo, «La actividad de la filología a la luz de la experiencia de Nietzsche», Philosophica Malacitana, Suplemento ${ }^{2} 2,1994$, pp. 13-38. 
iniciada por Lessing. Frente a esta actitud vital, fue desarrollándose paulatinamente una filología auxiliar pensada para fijar los textos que la filología del espíritu comentaba. Mirado con la retrospectiva actual, el resultado es bien elocuente: los filólogos incapaces de crear, los que practican la letra plana y uniforme introdujeron sobre la libertad del espíritu y sobre la nobleza del arte y de los textos rescatados del pasado, el control férreo del rigor, de las fuentes y de los datos; y esto, que era en el proyecto de la modernidad filológica un simple elemento auxiliar, por metonimia, llegó a provocar una fagocitosis del espíritu de las obras que fijaba. Los herederos de esa filología de la palabra son actualmente los filólogos formales, esto es, fonólogos, lexicógrafos, historiadores de la lengua, lingüistas, ciertos críticos literarios e historiadores de la literatura. Un poco utópicamente reclamaba yo en ese artículo que estaba absolutamente convencido de que en algún lugar - y no sabía en cuál- muchos filólogos genealogistas -y tampoco sabía quiénes eran-, que habían saboreado las dulces uvas del espíritu salvaje de Dioniso, tendrán, tendremos, que salir algún día de la cueva de Zaratustra. Igual que entonces, sigo sin saber cómo enfocar el problema. Pero nosotros, los filólogos de la tradición, detestamos lo que quiero bautizar en este artículo con el horrendo nombre de la filisteofilología.

Por ahora sólo sé que la charlatanería es una filología del espíritu cuyo último vestigio fueron los textos que Nietzsche escribió entre 1869 y 1875 , en particular el discurso inaugural que pronunció en el aula del museo de la Augustinergasse el 28 de Mayo de 1869, apenas un mes más tarde de haber llegado a Basilea, con el título de «Homero y la filología clásica», en el que dejó sentados varios principios muy importantes: «No existe - dijo- en nuestro tiempo un estado de opinión concreto y unánime sobre la filología clásica», la filología - como ahora también sucede - vive del crédito de varias disciplinas diversas y, por tanto, todo esto genera una incertidumbre y cierto escepticismo en los problemas filológicos. Así que Nietzsche tuvo que defender la pureza de la filología - esto es, su espíritu libre y creativo, soñador de historias y leyendas- con la ayuda de los artistas. Recordó a los filólogos el terrible reproche de Schiller: sólo ellos destrozaron la corona de Homero. Opuso por primera vez el arte a la ciencia, y planteó con toda su crudeza la cuestión homérica: sea quien fuere el que responda al nombre de Homero, los filólogos son incapaces de comprender el Ideal. Incluso actualmente los filólogos de la letra siguen sin saber lo que esta palabra significa. Así que la solución es ya muy conocida, pues Nietzsche tiene que invertir una sentencia de Séneca: «Philosophia facta est quae filologia fuit», e inmediatamente aclara: «Con esto quiero expresar que toda actividad filológica debe estar impregnada de una concepción filosófica del mundo en la cual todo lo particular y simple sea condenado como algo despreciable, y sólo quede en pie la unidad del todo» ${ }^{9}$. Frente al formalismo

9 F. Nietzsche, «Homero y la filología clásica», en Obras completas, Madrid, Aguilar, 1932, vol. V, p. 26. 
filológico, ajeno a la consideración del lenguaje como pulsión artística, hay una filología, de la que me declaro firme partidario y el primero de sus exegetas contemporáneos, que describe los dioses ligeros de un país mágico para la que era más importante vivir la Idea antes que pensar la Idea. En La mirada griega he llamado a esto: Vivir el Ideal.

Los filólogos - tan empeñados durante la primera y la segunda modernidad en actividades prácticas de lenguaje, la cuales nada tienen que ver, aunque sea una paradoja, con ninguna de las praxis del arte - han sustituido el vivir por el pensar. Su lugar, del que cada vez los filósofos se han apropiado con mayor insistencia, se ha visto convertido durante la contemporaneidad en campo de pensamiento. Sólo una parte exigua de la filología heredera del estilo de Nietzsche reclama, reclamamos, que hablar no es más que pensar, y que no puede haber un lenguaje que se convierta en lengua de la gran masa social y que sirva como producto de uso para hablar y comunicar, si ése no es el lenguaje objeto de la filología. Ese lenguaje pertenece también a la interpretación, es el lenguaje enigmático soñador de mundos, cuyas reglas ni siquiera necesitan ser incorporadas a una teoría general de los signos. Sobre ese lenguaje, que es el de las exégesis, nada han querido saber los filólogos formales. Pero éstos deberían recapacitar sobre este pensamiento de Foucault: «A la pregunta nietzscheana: ¿quién habla?, responde Mallarmé; y no deja de retomar su respuesta cuando dice que quien habla, en su soledad, en su frágil vibración, en su nada, es la palabra misma - no en el sentido de la palabra, sino en el de su ser enigmático y precario $\longrightarrow{ }^{10}$. Los filólogos sabemos mucho del sentido, pero nada del enigma. Y resulta que en las grandes cuestiones - aquellas en las cuales Foucault situaba la distancia entre la inquisición de Nietzsche y la respuesta de Mallarméparte de ese enigma se revelaba en el origen mismo de las preguntas: «¿Qué es el lenguaje? ¿Qué es un signo? Lo mudo en el mundo, en nuestros gestos, en todo el blasón enigmático de nuestras conductas, en nuestros sueños y en nuestras enfermedades, todo esto ¿habla?, ¿cuál es su lenguaje?, ¿según qué gramática? ¿Es todo significativo, o qué, y para quién y de acuerdo con qué reglas? ¿Qué relación hay entre el lenguaje y el ser, y se dirige siempre al ser el lenguaje, cuando menos aquel que habla verdaderamente? ¿Qué es, pues, este lenguaje que no dice nada, que no se calla jamás y que se llama 'literatura'? $»^{11}$. Habrá, pues, que tener cuidado cada vez que los filólogos se decidan a interrogar.

Así que la exégesis es un firme contrapunto del formalismo. La exégesis que aquí propongo es la prolongación moderna de aquella charlatanería que caracterizó al inefable Comentario que se adueñó del pensamiento del siglo XIX. La exégesis es un discurrir interminable y sin sentido sobre la esencia inasible y

\footnotetext{
10 M. Foucault, Las palabras y las cosas, México, S.XXI, 1971, p. 297.

$11 \quad$ Id., p. 298.
} 
artística del lenguaje, esencia que está contenida en algunos usos lingüisticos. Recuperaremos para aquélla una advertencia homóloga al famoso letrero de la Academia de Platón: «Que no entre aquí —en el reino de la filología_ quien no sepa interpretar». En cierto modo, es un ejercicio entusiasta, en el sentido platónico del Fedro o del Ion, que lo vive el intérprete como un ejercicio de liberación, más o menos como si fuera un tipo especial de sublimación que tuviera lugar a través de un sueño. Es un entusiasmo de tal naturaleza que un exegeta sólo puede contener un sentimiento sobrio - y por ello parece cercano a la reflexión-cada vez que interpreta, pues como se trata de transmitir un tipo especial de experiencia, tiene que huir de todo sentimiento estridente para adaptarse a la obra de arte que comenta. De todas formas, desde un punto de vista teórico, la exégesis es una tremenda apuesta en favor del artista-intérprete, y nació con la intención de devolverle a la filosofía su quiliasmo. Por eso el campo de sus objetos es tan amplio: textos literarios, lingüísticos, filosóficos, artísticos, o cualquier otro. Con ello se configura como un movimiento de vaivén, como una especie de nuevo círculo filológico (Schleiermaier), centrado sobre el pasado, y que responde a una concepción del lenguaje como sujeto artístico de la Historia del Saber. Lamentablemente, los lingüistas - todos los filólogos de la forma - mantienen en general una posición muy distante, puesto que sólo ven las lenguas como objetos de conocimiento. Esto es sin lugar a dudas una gran aberración que no debe de extrañarnos porque ciertos horizontes de incongruencias son una de las grandes caracterizaciones de la contemporaneidad.

La mayor de todas las contradicciones fue sin duda la responsabilidad por la conversión del lenguaje en objeto, la cual tuvo que ser asumida por la filología en el momento de su creación a principios del siglo XIX a causa de la presión ejercida por los filólogos de la palabra. Foucault dejó aclarado que, desde el momento en que el lenguaje se repliega sobre sí mismo - lo que tiene lugar en esta época-, conocer el lenguaje no era tanto profundizar en la labor de conocer como aplicar los métodos del saber en general a un dominio particular de la objetividad. Esto hizo que durante la modernidad los métodos de interpretación hayan estado enfrentados a las técnicas de formalización, que la interpretación fuera un análisis destinado a sugerir y que, sin embargo, la formalización fuese una técnica orientada a sojuzgar y a dominar. De una manera, que no es ni mucho menos hiperbólica, podríamos decir que mientras las exégesis callan, los formalismos hablan. Tendremos que superar incluso el planteamiento de Foucault, sobre todo si se tiene en cuenta que casi treinta años después de que éste escribiera Les mots et les choses ya no nos presiona la separación entre interpretación y formalización. Y aunque sepamos que la horquilla dibujada por tal separación «no se hunde demasiado lejos en nuestra cultura» y que el fundamento de ambas lo constituye «el ser del lenguaje», nos congratula saber 
que la imaginación y la creatividad que asumen los métodos de interpretación y exégesis no tienen nada que ver con el burdo esquematismo y el rigor normativo impuestos por la consideración de la lengua objeto que analizan las técnicas de sistematización y formalización, aunque en algunos casos se revistan hoy con el cómodo rótulo de la sociología.

III.

En la exégesis que quiero desarrollar, confluyen variados procedimientos, a excepción de los formales. Si se tiene en cuenta que una de las características más firmes de la contemporaneidad es la de la pluralidad de interpretaciones, entonces se comprenderá fácilmente cuál es la actualidad de las exégesis. Incluso su propio nombre tampoco es casual. Lo prefiero al de paráfrasis, glosa, comentario, escolio, etc., ya que es mucho más que todo eso. Su nombre está ideado para practicar una anfibología: parece que remite al Libro Sagrado y que plantea una convergencia metonímica con la teoría del comienzo verbal -i.e., la palabra bíblica-, cuando en realidad lo que hace es confrontar su objeto con la experiencia de su origen. El origen es siempre el sujeto, el otro de tu otro. Y la confrontación del sujeto con el objeto no se hace desde el punto de vista de un Juicio autorizado para separar ambos elementos. Como los procesos de la locura y de la muerte son los bordes que conforman los límites en que la interpretación infinita se confunde con la obra de arte comentada, aquella confrontación se lleva a cabo desde la perspectiva de la unificación completa de ambos elementos. Un espíritu desintegrado por la locura puede ser homosemántico, y ante el tránsito de la muerte, ¿quién puede negar que tanto el objeto seleccionado como el sujeto que la padece configuran una ligazón que en nada se diferencia de la complicada estructura categórica del Ser?

La perspectiva de la unificación sujetolobjeto es, por consiguiente, la confrontación en el espacio de lo que es y no puede ser otra cosa. Las exégesis entienden el hecho literario, lingüistico y artístico en general, como la transferencia o la confrontación permanente de un objeto pasivo con un sujeto activo. Esa transferencia es un ejercicio de reproducción. Por eso la gran literatura es un acto que reproduce el objeto en el sujeto, el procedimiento que confronta en una experiencia inédita la realidad con el mito o con el universal fantástico. La abstracción por géneros, que es un universal dianoético, discursivo o intelectual, se convierte en arquetipo una vez que la reproducción ha tenido lugar. Quien no entienda esto tendrá una concepción sentimental, emotiva o folklórica de la literatura y del arte, confundirá la literatura egregia con la literatura mimética, y no sabrá que la gran literatura es una cadena de sofismas. Quien no entienda esto no se habrá percatado nunca de que Homero - sea quien fuere el que responda a ese nombre- fue el primer nostálgico de la historia, que los grandes 
sueños fueron generados siempre por profundos sentimientos de añoranza y que la soledad de Cervantes, Mozart, Goya o Kafka únicamente es explicable como una abstracción dianoética una vez que ha tenido lugar un acto de reproducción.

Las exégesis no sólo han nacido para contribuir ellas mismas al juego de la reproducción. Conviene recordar que les ha tocado vivir un momento histórico en el que han necesitado llenarse de orgullo para enfrentarse descaradamente a los métodos formales. Si desde Kant las formas pavonean su estado de un libre juego del espíritu en una representación dada, en el universo de las exégesis el juego de sus palabras reviste un carácter absoluto: las exégesis oponen el misterio a la libertad formal, esto es, la infinitud de lo libre a la sujeción de la libertad. A veces, la libertad es una categoría cautiva, y por ello frente a la libertad del juego de las formas (Kant), deseo resaltar la reclamación de absolutos que se encierra en el arte de juzgar y comentar (exégesis). La exégesis parece metafísica porque, después de acercarse al mundo griego, también está convencida de que la voluntad de Schopenhauer o la cosa en sí de Kant son ocurrentes transposiciones de la primitiva Idea de Platón; y, no obstante, no es una metafísica, si se tiene en cuenta que detrás de la palabra ser la exégesis no vislumbra ninguna trascendencia religiosa o espiritual. En realidad, su objeto se detiene ante la nada que es, y a este objeto lo funda como sistema. Fundamentalmente, aspira a establecer una fórmula sobre el no ser y sobre el origen de la muerte. Y su estructura consiste en la ordenación de un lenguaje vacío que no tiene realidad fuera de su entorno. Por eso hablé una vez de la posibilidad de fundar una teoría del vacio literario.

Enuncié esa teoría a propósito de la obra de Julio Calviño ${ }^{12}$, uno de los mejores narradores contemporáneos de cuentos en España. Ahí hablé del absurdo, de la ausencia de finalidad de la naturaleza, del carácter ficticio de la realidad inmediata y del eterno retorno, hablé de saber —desde la preeminencia social que supone ser artista en nuestro entorno- y de comprender que el absurdo eterno es el efecto conceptual de exprimir el ser y que, entonces, colocado como un dios encima de la escritura, ya podíamos proclamar el sujeto cero y estar contra el sujeto en cuanto que categoría que dignificó todo sometimiento y toda represión moderna. Pero al mismo tiempo era inevitable asumir la imagen de un sujeto libre, aunque éste fuera una entidad ilusoria, por cuanto se hacía necesario para poder crear de la nada, del cero, y poder retornar a un final en la nada. Decía yo que todo esto formaba parte del gran objetivo de las exégesis. $Y$ a este nihilismo patético - del que la muerte y el fracaso y el sexo y la bestia y la locura constituían su vertiente prosaica-, lo denominé vacío, y vi que su efecto

12 M. Crespillo, «La teoría del vacío literario en los cuentos de Julio Calviño», Cuadernos Hispanoamericanos, $1989, \mathrm{n}^{\circ} 467$, pp. 148-156. Una versión ampliada de este trabajo apareció con el título «Julio Calviño, fabulador del vacío», en Analecta Malacitana, Vol. X, 2, 1987, pp. 369404. 
más inmediato era un abismo, un hueco, la nada literaria. El vacío literario era como aquel espacio del que hablaba Blanchot, justo en el momento en el que el ser desaparecía en el horizonte y su huella —que era la nada- conseguía hacerse literatura. Yo pedía entonces invertir aquella representación de Rilke, Heidegger o Blanchot («el poema - la literatura - parece ligado a una palabra que no puede interrumpirse porque no habla: $e s{ }^{13}$ ), retomar la experiencia de Mallarmé y pensar en la posibilidad de una realización del poema en la que la palabra no fuera apariencia de algo que hubiera desaparecido. Había que confiar en que detrás de la palabra sólo existiera la huella de su propia negación. Al mirar, no era posible encontrar nada, sólo un inmenso vacío. El vacío literario surge cuando un tiempo circular (retorno del absurdo infinito) origina la detención de un sujeto que, por más que transgrede un orden, fracasa y muere hasta convertir su nada en literatura. A causa de esa inmovilidad, el sufrimiento se hacía infinito dentro del vacío literario. La literatura europea había dado pruebas cuantiosas de este dolor. Antes de sucumbir, Hölderlin decía en su Hyperion: « $i$ Ah, pobres de vosotros los que sentís todo esto, los que tampoco gustáis de hablar del destino humano, los que os sentís también cada vez más atrapados por la nada que reina sobre vosotros, fundamentalmente convencidos de que nacemos para nada, de que amamos una nada, creemos en nada, nos esforzamos por nada, para hundirnos poco a poco en la nada...! ¿qué puedo hacer si os flaquean las rodillas cuando pensáis seriamente en ello?» ${ }^{14}$. La muerte, el poder, el deseo... hacen que el vacío literario pueda causar la impresión de un discurso cerrado sobre sí mismo, pues al ser su Otro el hueco, el abismo y el infierno parecería que no hay posibilidad de prolongación en el tiempo. Y, sin embargo, Nietzsche lo dijo muy claramente: el absurdo infinito, es decir, la única posibilidad real que tiene la literatura y el arte de sobrevivir en un mundo absurdo - donde no hay nada más simple que un nihilista prosaico - es oscurecer su ser hasta tal punto que no puedan acceder a su interior la pléyade vulgar de todos aquellos individuos que no pertenecen a la aristocracia de la oquedad. Un aristócrata de la oquedad es aquel que comprendió que en la actual fase de desarrollo de la segunda modernidad solamente se puede llegar a ser intérprete tras colocarse la máscara de exegeta. Es preciso ser un dios para morir, pero asimismo es necesario ser un dios para reírse de la muerte. En el punto más alto de nuestro destino sólo la angustia y la nada, y también la escritura que, como lugar del vacío, tampoco contiene nada. Así pues, ante la exégesis, no encontramos sino el sueño y el espejo y la semejanza y la escritura y el deseo y la angustia y la nada y dios y la muerte y la mentira y la risa, la gran risa de la muerte.

13 M. Blanchot, op. cit., p. 31.

14 F. Hölderlin, Hiperión, Madrid, Hiperión, 1986, pp. 70-71. 
IV.

Un nihilismo que no sea espontáneo, y que logre sujetarse a leyes artísticas sistemáticas de las que se derive una arquetipología de lo dianoético, exige que la exégesis se fundamente en una serie de supuestos.

El primero de ellos es el rechazo de la historicidad. La exégesis valora hasta tal punto el poderío del carácter histórico de los fenómenos de lenguaje que su negación sistemática únicamente puede fundamentarla en el pasado. Hay un pasado próximo en el que la exégesis prolonga su comentario. Se trata de ese mundo infinito constituido por los valores ideales del siglo XIX. La exégesis ve en Hegel al exegeta de la Idea, en Schopenhauer al exegeta de la cosa en sí, en Marx al exegeta del valor, en Nietzsche al exegeta de la palabra, en Freud al exegeta del sueño... Es como si una idea clave en filosofía fuera una palabra clave en el quiliasmo del lenguaje. En tal sentido, la inmensa raíz nietzscheana de la exégesis permite ligar un proyecto sobre la historicidad verbal con la idea del eterno retorno de lo mismo. En más de un aspecto la libertad infinita que propugno está ligada a la constatación de Zaratustra sobre el carácter curvo de la verdad y, sobre todo, a la gran idea de Nietzsche de que la eternidad tiene un carácter circular, un sendero también curvo. Lo cual significa que el tiempo en que el universo actúa es infinito, que el tiempo transcurrido hasta la época actual ya ha existido y que, por tanto, todo desarrollo, acción o experiencia han tenido lugar alguna vez. En su interpretación, tanto hacia adelante como hacia atrás, el tiempo se mueve por repeticiones. Por eso cuando hablo del arte como experiencia que se agota en lo infinito, en el claro de una abertura interminable, me refiero al agotamiento de cada experiencia individual como exploración de un camino inédito, no a la aventura misma de agotar en la experiencia, la cual sí es permanentemente retornable desde el momento en que no es una experiencia atemporal, pues se incrusta en la infinitud del tiempo y contribuye a enriquecer el carácter permanente del ser mismo del tiempo.

La idea del retorno como principio selector al servicio de la fuerza de la naturaleza - «todo vuelve y retorna eternamente», decía Nietzsche— permite que alrededor del arte pueda formalizarse un pacto entre la muerte, la repetición y el fracaso: «El recomienzo, la repetición, la fatalidad del retorno, todo aquello a que aluden las experiencias donde el sentimiento de extrañeza se une al ya visto, donde lo irremisible toma la forma de una repetición sin fin, donde lo mismo está dado en el vértigo del desdoblamiento, donde no podemos conocer, sino reconocer, todo esto alude - decía Blanchot- a ese error inicial que puede expresarse bajo esta forma: no es primero el comienzo sino el recomienzo, y el ser es precisamente la imposibilidad de ser una primera vez» ${ }^{15}$. Cuando decimos que una obra es creada de la nada, aludimos a su comienzo, pero, si nos fijamos

Blanchot, op. cit., p. 232. 
detenidamente, este comienzo marca su inicio a partir de la idea del arte, y únicamente esta idea se vincula a un recomienzo incesante y al eterno retorno de lo mismo.

Así pues, podemos afirmar que la exégesis es ante todo pura exégesis de la voluntad, y sólo en cuanto que mira su pasado, y todo lo que es el origen del ser, se encuentra con la historicidad verbal. Sin embargo, como cada uno de sus recomienzos se comporta como un a priori, esto obliga a formular una teoría sobre el a priori histórico, cuyo efecto más importante sea la sustitución de todos los historicismos -incluyendo las historias materiales, ideales o mentalespor una simple constatación: las síntesis a priori son condiciones sine qua non para que transcurra la Historia. Tales síntesis, equivalentes mentales del fatum de la vida, gobiernan los fundamentos históricos que remueven las exégesis. Sólo así se fundaría un neokantismo funcional en el que los valores heroicos podrían ser recuperados para el futuro de los universos artísticos si se organizara una exégesis de la vida trágica en la que se lograra fijar categóricamente la diferencia entre Arte Egregio y Arte mimético o imitativo.

Un hombre son dos hombres, decía Corneille, y a Borges le gustaba tanto esta idea que se la adscribió a Menard. Permítaseme alterar la idea de Corneille y la de Borges, concédaseme el poder de decir que "un nombre son dos nombres», con lo que quiero manifestar que un artista es doblemente artista i.e., artista egregio - cuando cobra conciencia del juego de las reproducciones. En ese momento, Beethoven, hijo de un modesto cantor de la capilla de Bonn, de personalidad prometeica y que cree en la libertad infinita, ya puede tratar con altanería a príncipes y nobles. Frente al arte imitativo, el Arte Egregio es doblemente representativo, y su comentario, que es la exégesis, reclama también una representación duplicada capaz de asumir dos términos en uno. Una especie de comentario profano está pensado para incorporar dos nombres en la palabra única llamada exégesis.

Otro supuesto de la exégesis es el rechazo de todo carácter científicopositivo. Las exégesis comprenden las excelencias que rodean la división ciencias de la naturaleza/ciencias humanas y creen que las primeras son nefastas para el desarrollo del espíritu del hombre. Por ello son hostiles a lo que comúnmente se entiende por progreso, contrarias al bienestar ligado al desarrollo tecnológico, y por esa razón un exegeta tiene que celebrar festivamente el divorcio definitivo que se produjo en el inicio de la modernidad, en especial tras la obra de Kant, entre los dominios científico-positivos y los reinos de las humanidades. Lo más negativo de la idea de progreso es que ésta encierra su propio mundo, un mundo cuyo carácter sensible impide al hombre fundar relaciones que no tengan que ver con lo inmediato, y de ahí su distanciamiento con cualquier reflexión que no reporte algún grado de bienestar material, su radical distanciamiento con la experiencia del arte y de la muerte como vivencias llevadas al límite. Desde Nietzsche sabemos que el progreso es una idea falsa, y 
no simplemente, como quería el genealogista, por el hecho de ser moderno, sino fundamentalmente porque es una fuerza disgregante: renuncia a las voluntades de tradición, de autoridad, de responsabilidad para con los siglos futuros, de solidaridad entre generaciones futuras y pasadas in infinitum. El progreso es el mayor síntoma de decadencia de los pueblos, y un buen argumento para explicar históricamente el debilitamiento de los sistemas de poder. Incluso como elemento de prospectiva, será un principio que a largo plazo demostrará que la circularidad de la barbarie tiene forma de ley.

No se puede creer en las excelencias del objeto, y sí en la sobrevaloración del sujeto. El eje categórico sobre el que se fundamenta la distinción moderna entre naturaleza y cultura es el enfrentamiento entre un sujeto y un objeto. La transferencia que se origina con toda reproducción es un movimiento que va desde un objeto a un sujeto. El sujeto es un elemento activo por el que suelen tomar un partido inequívoco las exégesis. $Y$, al inclinarse del lado del sujeto, la ceguera es siempre una de sus grandes posibilidades. A diferencia del filósofo, un exegeta puede estar ciego. Más aún, un exegeta siente que es un orgullo eso de estar ciego. Esto es muy importante por cuanto lo que dota de inefabilidad a un comentario ilustre es la carencia de miedo a tropezar o a cometer lo que los científicos, culturalistas o eruditos en general llaman «errores», sean del tipo que sean. Así pues, después del gran divorcio disfuncional entre los atributos del Ser, que tuvo lugar con el inicio de la modernidad, la exégesis mira esperanzada la actitud marginal de un sujeto y ve su porvenir como una simple actitud poética. Esta actitud es de una extraordinaria perspectiva.

Es verdad que aquella marginación tiene mucho que ver con la autodestrucción, la irracionalidad y el silencio. Sin embargo, ante el enfrentamiento del lenguaje objeto y las agresiones metodológicas que surgen como resultado de la incapacidad para valorar correctamente que toda la creatividad del lenguaje reside única y exclusivamente en el poderío de un sujeto, la filología del espíritu no puede ni debe guardar silencio. Aun sin querer, tendrá que arremeter contra aquellos sistemas que surgen de la consideración de las lenguas como objetos de conocimiento, y en especial habrá de manifestar su gran hostilidad contra las proliferaciones del arte mimético. En nombre de ese espacio interior que muchos ignoran, incluso cuando no hablan, y en nombre del silencio, que muchos no guardan incluso cuando callan, un exegeta no puede permanecer impasible. Orgulloso de su ceguera, tendrá que clamar contra los estudiosos del lenguaje por olvidar que toda lengua es en su parcialidad la parte de un proceso de conciencia, en el que es mucho menos importante el sistema de sus elementos acústicos o las reglas de su funcionamiento o el utillaje social de sus signos, que su capacidad de creación de mundos, en la que el objeto se acomoda a los fines y a la trascendencia de los trozos de discurso, los cuales necesitan tener una vida autónoma. La filología de la cosa es una filología de la vida. Y llegado el caso, estoy convencido de que esos trozos serían capaces de mover el objeto a golpes 
de látigo. La grandeza de las lenguas no depende del conocimiento de sus mecanismos ni de los usos regulables de sus hablas. Es el sujeto de los trozos de discurso, el poderío de su imagen, y el dominio de los universos reales e imaginarios lo que está en juego en la anulación del objeto por un flujo incesante de creatividad. Ante esta grandeza, la lengua objeto hace tiempo que me parece un concepto indigente. Pero los filólogos del espíritu saben que esto es así desde que nació la filología en los primeros albores de la modernidad.

De ningún modo se podrá admitir el desarrollo de la mimesis en el campo de las humanidades. Al observar el esquema de desarrollo de los recintos humanos, las exégesis inventan la categoría de mimesis no para referirse a cualquier imitación de la naturaleza que contenga un carácter artisticoaristotélico -y se debe saber que cuando hablo de arte mimético como unidad opuesta al Arte Egregio sí me estoy refiriendo a esa imitación-, sino para indicar que lamentablemente las ciencias humanas son insaciables a la hora de copiar técnicas, procedimientos, objetos y métodos de los saberes positivos. Por ese motivo es fundamental para la mimesis establecer la distinción categórica entre constitución y aplicación dentro de los reinos interdisciplinarios. La constitución intradisciplinar siempre es legítima. En cambio, la aplicación entre disciplinas es una actitud completamente repudiable, muy propia del trabajo mimético, y el gran fundamento de la filología de la letra. Los filólogos formales necesitan establecer relaciones exteriores entre disciplinas diferentes para poder legitimar su carencia de sujeto. Pero es, al fin y al cabo, la epistemología de la preferencia la que interviene una vez más ${ }^{16}$. Si se rechaza el objeto producido como mimesis en el reino de las humanidades es porque los recintos humanos que practican tales mimesis solamente pueden imitar los reinos cientificopositivos cuando son capaces de inventar sus objetos. Un objeto inventado es un objeto producido. Y por eso la diferencia entre un objeto de conocimiento (u objeto general) y un objeto real se reemplaza en las disciplinas que practican la mimesis por una diferencia entre un objeto producido y un objeto real. El objeto producido es un objeto intradiscursivo que sólo tiene realidad para aquellos discursos que lo inventan. Desde el exterior, tales objetos revisten un carácter imaginario y, desde luego, así son contemplados por las exégesis.

En el lado opuesto de las exégesis está el universo de las formas. Ese universo, que arranca desde Kant, y cuyo rechazo es uno de los grandes objetivos de la filología de la cosa, está estrechamente ligado al positivismo y, en especial, al proceso de autonomía que sufrieron por entonces todos los reinos del Saber. El positivismo es un horizonte imaginario en el que los discursos sobre el hombre logran su autonomía convirtiéndose en saberes. Un saber

16 La preferencia es uno de los fundamentos más importantes de mi Historia y mito, y todo cuanto sé sobre esta epistemología lo escribí allí en innumerables sitios. 
autónomo es un dominio de carácter epistemológico al que se le asigna un objeto de conocimiento siguiendo un paralelismo con los dominios científicos, pero este paralelismo es el resultado de un falso proceso de metodología positivista, ya que mientras los discursos de las ciencias transforman su aparato conceptual para conocer su objeto, los saberes autónomos se fundamentan en el diálogo entre un sujeto y un objeto, independientemente de que estas categorías sean reales o inventadas. El origen inmediato de la filología de la palabra y la génesis remota de sus disciplinas académicas como son la Linguística o la Historia de la Literatura - con todas las ramas y subdivisiones que ambas han logrado establecer- están en esos saberes autónomos que surgen con el positivismo. Salvo en su tramo final, en el que existen grandes perspectivas de resurgimiento, toda la historia del siglo XX ha representado el mantenimiento de una ignorancia, cuando no de un rechazo profundo, de la exégesis como método de análisis en el horizonte de la cultura. Este rechazo se hizo en nombre de la forma. Nietzsche fue el último filólogo del espíritu, y su obra pertenece por completo al siglo XIX. Pero la exégesis moderna, pensada como prolongación de la filología del espíritu, repudia las miserias y degradaciones de los análisis formales, y hay que reconocer que afortunadamente, conforme pasan los años, las perspectivas de rechazo de las técnicas formales son cada vez más esperanzadoras. Aunque el desarrollo del siglo XX ha ido conociendo sucesivamente el auge de doctrinas y movimientos ligados al universo de las formas -i.e., formalismo ruso, estructuralismo, semiología, neoformalismo, etc.,- - todos estos movimientos, sin embargo, conforman el objetivo de destrucción más espectacular que se trazaron inicialmente las exégesis como reto.

Escribí en Historia y mito que la diferencia mayor entre las técnicas formales y las exégesis consiste en que aquéllas unen, y en que éstas separan, en que los formalismos llevan cien años intentando arreglar el divorcio que se produjo a fines del siglo XVIII entre el sujeto y el objeto, mientras que las exégesis no pretenden reconciliaciones. Los modelos de mimesis, regidos por técnicas formales, han nacido para unir lo que está definitivamente roto; no obstante, los exegetas nos negamos a este arreglo, creemos en el juego de la representación y en el entretenimiento de la reproducción, pensamos que la reproducción scrá siempre una noción especulativa y no un instrumento de conocimiento, que la reproducción sirve para jugar, pero no para establecer un juego libre, sino un juego absoluto y trascendente. Aunque parezca una paradoja, un juego absoluto no necesita revelar ninguna verosimilitud, lo cual caracteriza más bien a las formas libres, que sí requieren asociarse a la lógica del sentido. El juego absoluto revela una verdad desde la perspectiva genealógica de su valor, esto es, se configura como una hueste simbólica asociada a la Verdad del lenguaje o de la obra de arte entendida como desocultación del ser. Se trata de un juego absoluto que manifiesta la esencia general de las cosas fijando la verdad del ente $y$, por consiguiente, se refiere a la esencia de lo verdadero y llega a conformar la 
Verdad de una trascendencia que en cierto modo termina afectando a nuestro conocimiento de la realidad.

El juego absoluto de la reproducción —el que corresponde a esta Verdadconcierne al ente que está en el ser, bien entendido que al ente en su totalidad. $Y$, como fijó Heidegger, en el centro del ente total existe un lugar abierto que es un claro, el cual no está circundado por el ente, sino que que más bien rodea a todo ente como la nada, que apenas conocemos. Así pues, podríamos establecer una diferencia entre las formas del libre juego que operan con mimesis reales y las obras de arte que instalan la Verdad en su trascendencia hasta convertirse en ejemplares únicos, si lográsemos destacar que en el punto máximo de la creatividad del lenguaje las obras se encaminan siempre hacia una abertura infinita, es decir, hacia lo que nunca fueron y hacia lo que nunca más volverán a ser. Se dirigen hacia la gran e inestable experiencia de lo inédito. Se orientan hacia la instantaneidad del presente, y dejan de tener relación alguna con la historia. Tal experiencia, que abre al ente hasta lo inconmensurable - apertura que, no olvidemos, promueve la instauración de la Verdad — configura la grandiosa tentativa de la creación artística. Y como aquella que es la única Gran Verdad en el estadio ontológico, esta otra Verdad, que adviene en un proceso de desocultación, es el Gran Arte, la Poesía, aquélla a la que Heidegger definió como el decir de la desocultación del ente. El lenguaje, se convierte entonces en «el acontecimiento de aquel decir en el que nace históricamente el mundo de un pueblo y la tierra se conserva como lo oculto ${ }^{17}$. Es el nuevo cáliz profano de $E l$ pan y el vino. Al fondo, Hölderlin, aunque sea un misterio incomprensible para los filólogos de la palabra.

El Arte Egregio sabe bien que sólo el placer de la muerte puede igualar al acto de crear de la nada. El encuentro de la nada con un abismo, tras del cual esa misma nada permanece y continúa existiendo, origina que la reproducción de las exégesis no necesite asociarse a verdad cognoscitiva alguna. La trascendencia del juego absoluto a que se llega con la reproducción, se liga al simple hecho de que ayuda al hombre a soportar la vida. Es una trascendencia ligada a la ficción, como sucede con las formas artísticas o religiosas, por más que sea una mentira necesaria para sobrevivir. De ahí que los mundos de representaciones y reproducciones pertenezcan al horizonte de la exégesis, y no a reinos científicos o a modelos de mimesis. Todo el poder imaginativo del lenguaje está, pues, en juego. $Y$ sería lamentable que las exégesis no se lo apropiaran de manera definitiva. Tal como puse de manifiesto en la «Teoría del comentario de textos», resulta que cuando se produjo el divorcio entre las ciencias de la naturaleza y las disciplinas humanas a comienzos del siglo XIX, Hegel tuvo que reconocer que la obra de arte era incapaz de satisfacer nuestra última necesidad de lo Absoluto. Su más alto destino lo compartía con la religión y con la 
filosofía, a pesar de que, a diferencia de éstas, el arte promoviera representaciones sensibles de la Idea. De ahí que nos sintamos más libres que en otros tiempos en los que las obras de arte eran la expresión suprema de la Idea. Respetamos y admiramos el arte, aunque ya no vemos en él, decía Hegel, la manifestación intima de lo Absoluto: «Los buenos tiempos del arte griego y la edad de oro del final de la Edad Media están superados. Las condiciones generales de los tiempos actuales no son muy favorables al arte. El artista mismo no sólo está desconcertado y contaminado por las reflexiones que oye formular a su alrededor, por las opiniones y juicios ordinarios acerca del arte, sino que toda nuestra cultura espiritual es tal que le es imposible, incluso con un esfuerzo de voluntad y decisión, abstraerse del mundo que actúa a su alrededor y de las condiciones en que se encuentra comprometido, a menos que rehaga su educación y se retire de este mundo en busca de una soledad donde pueda volver a encontrar su paraíso perdido. Desde todas estas relaciones, el arte es, en cuanto a su supremo destino, como una cosa del pasado. Por ello ha perdido todo lo que tenía de auténticamente verdadero y vivo, su realidad y su necesidad de otros tiempos, y se encuentra a partir de ahora relegado en nuestra representación ${ }^{18}$.

Después de Hegel el arte se ha dividido. Hay un arte mimético cuya ley de desenvolvimiento no ha permanecido ajena a la provocación de gozar el texto, a los sentimientos de placer y dolor que provoca. Y hay otro Arte Egregio, al que podremos llamar también Gran Estilo o Gran Arte, que tuvo que resolver a su manera los problemas mencionados por Hegel: «Se puede, por cierto, esperar que el arte se eleve siempre más y se perfeccione, pero su forma ha dejado de ser la necesidad suprema del espíritu. Podríamos hallar magníficas las imágenes de los dioses griegos y ver representados plena y dignamente al Dios padre, a Cristo y a María; sin embargo, esto no ayuda tampoco para hacernos doblar la rodilla $\gg^{19}$. Así que en lugar de manifestar lo Absoluto, hubo un arte, despućs de Hegel, que representó en sí mismo la pasión por lo Absoluto, proposición que debe entenderse de esta única manera: el arte se volvió un Absoluto. Evidentemente, esto implicaba un cambio cualitativo, pues no se trataba ya de aparentar lo Absoluto sino de ser lo Absoluto. Plantearé entonces la cuestión sirviéndome de los mismos interrogantes que usó Blanchot: «¿Por qué en lugar de disiparse en el puro goce de una satisfacción o en la vanidad frívola de un yo que huye, por qué la pasión del arte, ya sea en Van Gogh o en Kafka, se vuelve lo absolutamente serio, la pasión por lo absoluto? ¿Por qué Hölderlin, Mallarmé, Rilke, Breton, René Char, son nombres que significan una posibilidad en el poema, de la que ni la cultura, ni la eficacia histórica, ni el placer de un hermoso lenguaje dan cuenta,

Is G. W.F. Hegel, Introducción a la estética, Barcelona, Península, 1971, p. 36.

19

G. W. F. Hegel, Estética, I, Barcelona, Península, 1989, p. 95. 
una posibilidad que no puede nada, que subsiste y permanece como el signo, en el hombre, de su propio ascendiente? ${ }^{20}$.

Esta pasión por lo Absoluto transformó en gran manera la naturaleza del arte durante la segunda modernidad. Lo convirtió en una desmesura, en una hybris, en un descontrol, en un engaño indefinido que iba más allá de la violencia del poder, del saber o del deseo, y por esta vía volvió a reencontrar su pasado de infinitud, de nada y de vacío. Así como la naturaleza tiene horror al vacío, que siempre debe de ser cubierto por la necesidad, el arte, contrapunto de aquélla, ha vuelto a convertir la nada y el vacío en un mundo infinito y libre. Al negar tan desenfadadamente el deseo y permanecer inmóvil ante la evolución del transcurso del tiempo, el arte ha dirigido con más fuerza que nunca una mirada hacia la muerte. El infinito es la muerte, la falta de carencia, la incapacidad de desear, la renuncia a las fórmulas de poder o de conocer, la ausencia de las formas del sufrimiento y de los estigmas de la vida, es una muerte sentida en la distancia, que no es ni muerte personal ni muerte ajena, pese a que incorpora la posibilidad de interpretar todo un mundo hasta experimentar el desconcierto, hasta rozar las formas de lo ilícito y provocar el derrumbe brusco, el repentino colapso del espíritu. El arte se presta de este modo a una profunda labor de autodestrucción. Este fue el caso de Hölderlin, pero también el de Mallarmé, el horror de Igitur por la Forma Pura, el miedo a lo Infinito, al Azar y a lo Absoluto que aparece en esa Tirada de dados que nunca abolirá el Azar. Este azar refleja que la preocupación por crear puede ser tan agobiante como la experiencia misma de la muerte.

La representación y la reproducción que tanto honran al mundo de las exégesis son, por consiguiente, juegos trascendentes, combinaciones de totalidades y absolutos. El acto de la representación es el ofrecimiento de respuestas imaginarias, prácticas o teóricas, a cualquier pregunta o actitud artística posible; el acto de la reproducción es la realización de un engaño permanente - -de un guiño y no de una mirada fija - ante cualquier posibilidad de conocimiento. Huir del conocimiento es adoptar la actitud a que se refería Pessoa al decir que el poeta era un fingidor. El lenguaje finge incluso cuando parece que denota. Los lingüistas deberían saber bastante de esto.

$Y$, sin embargo, un exegeta no es un ingenuo. Sabe bien que la exégesis, aplastada en la última fase de la modernidad por el imperio de las formas, es como Prometeo frente a Zeus. La representación es el juego de sus inventos y la reproducción el juego de sus cadenas. Y sus interlocutores siempre serán seres errantes: Io aguijoneada, las Oceánidas compasivas, y nada más. ¿Cómo hablar con personajes que jueguen a representar el papel que Goethe o Schiller 
mantuvieron ante Hölderlin? Por eso aquel que quiera hacer uso de la exégesis y adueñarse de su sistema tiene que preparar su exilio interior, convertirse en un ser errante y recurrir a la opción del margen. Sentirse exiliado es profundizar en el reino de la mentira hasta su propio fundamento de verdad, comprobar cómo una experiencia imaginaria se difumina en la lejanía sin que podamos imponerle un límite. Se trata de defender la ficción del lenguaje como forma de la gran Verdad.

La representación, esquema en el que se entrecruzan imágenes hasta el infinito, poder persuasivo del mito ante el imperio del conocimiento, fue un sistema de creencias imaginarias mezcladas con verdades hasta fines del siglo XVIII. Participaba en toda festividad, le servía al poeta para identificar el cielo con la tierra, intervenía en los dominios de las ciencias confundiendo la atracción magnética con la simpatía o atracción de almas platónicas. Y la reproducción la encadenaba a la representación. Hipias, con todo derecho, confudía lo bello con una bella virgen, o con una yegua hermosa, o con el oro; ante un espejo, Ricardo II confunde al hombre con el rey; los molinos son gigantes para Don Quijote. El objeto se transfería entonces al discurso y la imagen, sumergida en el juego de la representación, permitía cualquier confrontación. Los grandes creadores de mitos artísticos —que no tienen parangón posible con los mitos de los modelos de mimesis - nunca asumieron bien la cultura de Sócrates y sabían que junto a la razón siempre había un hueco reservado para el éxtasis imaginario, para la irracionalidad perversa o para la sinrazón histórica. El éxtasis de la imagen es una experiencia distante del objeto en la que el artista, frágil vaso, se encuentra absorto en el mundo del olvido. El olvido es la muerte, la mayor de las experiencias del sujeto, aquello que impone como ley inexorable que no puede haber transferencia ni confrontación si el objeto no resulta excluido mientras transcurre la elaboración simbólica del tránsito. Una vez aniquilado el objeto, ya no es difícil encontrarnos ante gozosos poetas que, alegres, «vuelven a salir al valle». Sin embargo, este proceso es complicado y por eso no es generalizable: aun cuando sea digno de una sincera lamentación -muchos poetas y exegetas se malogran en la pugna que entablan con el objeto-, hay que reconocer que se trata de una experiencia impropia de las grandes mayorías. Sólo así se explica que la parte más exigua, y a la vez la más egregia de la cultura moderna, sea aquella que durante los últimos doscientos años propugnó incesantemente la necesidad de reclamar una visión artística del lenguaje. Naturalmente, la distancia que separa esta visión de la lengua sujeto de arte de aquella otra que concibe la lengua como objeto de la gran masa social es hoy por hoy inconmensurable. 